\title{
CONSENTIMENTO INFORMADO EM GENÉTICA FORENSE
}

\begin{abstract}
Rodrigo Grazinoli Garrido¹, Fabíola de S.R.G. Garrido²
Resumo: O consentimento informado é uma demanda ética e legal na pesquisa com seres humanos, visando a expressão autônoma dos sujeitos. Contudo, a autonomia fica em risco quando os envolvidos encontram-se vulneradas socioculturalmente. Nos casos forenses, a Lei 12.654 de 2012 exclui a necessidade do consentimento e torna obrigatória a doação de material biológico pelos condenados por crimes hediondos. $\mathrm{O}$ trabalho buscou avaliar o nível de vulneração dos sujeitos encaminhados a exames de DNA no Instituto de Pesquisa e Perícias em Genética Forense (IPPGF). Foram avaliadas a legibilidade e adequação normativa do Termo de Consentimento Informado (TCI) utilizado. Tentou-se também, identificar o grau de instrução e o hábito de leitura dos doadores para relacionar ao entendimento correto do processo. Pôde-se constatar que o TCI apresentava legibilidade acima da requerida à média dos encaminhados ao IPPGF, além disso, apresentava carências normativas. Por fim, verificou-se que muitos doadores têm restrito hábito de leitura e sequer liam o TCI quando consentiam. Os resultados da análise levaram a profundas mudanças no procedimento de obtenção de consentimento para exames de DNA forense no IPPGF.
\end{abstract}

Palavras chave: DNA, bioética, crime, gene

\section{Consentimiento informado en genética forense}

Resumen: El consentimiento informado es una demanda ética y legal en la investigación con seres humanos, respetando la manifestación autónoma de los sujetos. Pero, la autonomía queda en riesgo cuando los sujetos se encuentran vulnerados socioculturalmente. En los casos forenses, la Ley 12.654 de 2012 excluye la necesidad del consentimiento informado y hace obligatoria la donación de material biológico por los condenados de crímenes graves. Este trabajo buscó evaluar el nivel de vulneración de los sujetos sometidos a exámenes de ADN en el Instituto de Investigación y Pericias en Genética Forense (IPPGF). Fueron evaluadas la legibilidad y la idoneidad normativa del Término de Consentimiento Informado (TCI) utilizado. Se intentó, también, identificar el grado de instrucción y el hábito de lectura de los donantes para relacionarlos a la comprensión correcta del proceso. Se puede constatar que el TCI presentaba inteligibilidad por encima de la requerida en la media de los encaminados al IPPGF; además de eso, presentaba carencias normativas. Por fin, ha verificado que muchos donantes tienen insuficiente hábito de lectura y siquiera leían el TCI al consentir. Los resultados del análisis llevaron a profundos cambios en el procedimiento de obtención de consentimiento informado para exámenes de ADN forense en el IPPGF.

Palabras clave: DNA, bioética, crimen, gene

\section{Informed consent in forensic genetics}

\begin{abstract}
Free and informed consent is an ethical and legal request in research involving human beings, seeking the manifestation of autonomy of the subject. However, autonomy is at risk when those involved are socio culturally vulnerable. In forensic cases, Law 12,654 of 2012 excludes the consent and makes mandatory the donation of biological materials by those convicted for heinous crimes. The aim of the study is to assess the level of damage to subjects referred for DNA testing at the Instituto de Pesquisa e Perícias em Genética Forense (IPPGF). We assessed the readability and normative appropriateness of the Informed Consent form (ICF) used. The study also tries to identify the degree of literacy and reading habits of donors relating to the correct understanding of the process. It was found that the ICF has degree of readability above that of the convicted sent to IPPGF and also had normative needs. Finally, it was found that many donors have restricted reading habits and literacy. The results led to profound changes in the procedure for obtaining consent for DNA forensic trials in IPPGF
\end{abstract}

Key words: DNA, bioethics, crime, gen

\footnotetext{
${ }^{1}$ Instituto de Pesquisa e Perícias em Genética Forense do Departamento Geral de Polícia Técnico-Científica da Polícia Civil do Estado do Rio de Janeiro, Brasil

Correspondência: grazinoli.garrido@gmail.com

${ }^{2}$ Departamento de Ciências Administrativas e do Ambiente, Instituto Três Rios, Universidade Federal Rural do Rio de Janeiro, Brasil
} 


\section{Introdução}

A prova biológica, em especial a prova genética, alcançou posição de destaque nas varas criminais e de família $(1,2)$. Os testes de DNA tornaram-se, nas palavras de Gomes(1), um recurso "irresistível e imperioso", deixando de ser meios complementares de prova para se tornarem os fundamentos das decisóes dos magistrados. Ainda de acordo com essa autora, isto impulsionou a busca e obtenção de provas de licitude discutível, pois nem sempre respeita o consentimento de quem fornece. Calcando-se no princípio legal da proporcionalidade, a preservação de valores da sociedade sobreporia os direitos individuais(3).

$\mathrm{Na}$ verdade, o consentimento informado, a consulta à comunidade e a necessidade de ofertar benefícios aos sujeitos sempre foram acusados de retardar as pesquisas médicas e forenses com DNA(4). A despeito disto, para evitar discussóes processuais e possível nulidade da prova, órgáos de apuração criminal estão determinando a utilização de termos de consentimento para os procedimentos de DNA forense(2). Pois, é reconhecido que obter ou utilizar material biológico sem o consenso do doador fere os direitos fundamentais da pessoa, sobretudo, a integridade fisica e a tutela da privacidade(1).

O consentimento informado deve ser utilizado em todas as situaçóes nas quais se empregam tecnologias às pesquisas com seres humanos(5). $\mathrm{O}$ consentimento busca garantir a autonomia do sujeito da pesquisa(6). No entanto, é condição primeira que este sujeito entenda os procedimentos, desconfortos, benefícios, riscos e direitos envolvidos na ação(7).

Apesar do consentimento informado remontar às normas estabelecidas pelo Nuremberg Medical Trials(8), a assinatura de um documento ou termo de consentimento informado (TCI) por quem consente passou a ser praticada a partir de meados da década de 1960 , com a promulgação da Declaração de Helsink (1964) e do Pacto Internacional sobre Direitos Civis e Políticos (em vigor a partir de 1976)(9). Atualmente, várias são as declaraçóes internacionais, códigos de ética profissionais, resoluçóes e leis que determinam ou recomendam o uso de termos de consentimen- to(10). Dessa forma, a doutrina do consentimento informado alcançou status de norma dos direitos humanos internacionais, sendo reclamada por cortes ao redor do mundo(9).

É pacífico, no entanto, que não basta o consentimento do indivíduo, mas é indispensável que este tenha um conhecimento amplo de todo o processo do qual fará parte(1). Pois, a maioria das pessoas que buscam serviços lhes tranquilizem, encontram-se predispostos a utilizar qualquer ferramenta, especialmente quando estes são vulnerados cultural ou socialmente $(11,12)$.

$\mathrm{Na}$ a área forense, a predisposição se torna mais evidente e complexa, especialmente quando as pesquisas criminais fazem uso da informação genética(13). Nestes casos as preocupações éticas devem iniciar na obtenção das amostras biológicas, mas, sobretudo, seguir pelas etapas de tratamento, utilização e conservação dos dados genéticos $(13,14)$. Para tanto, devem-se seguir as recomendaçôes da Declaração Internacional sobre os Dados Genéticos Humanos, com vistas ao respeito da dignidade humana e a proteção dos direitos humanos e das liberdades fundamentais(15).

Todavia, a Declaração Internacional sobre os Dados Genéticos Humanos abre uma brecha para a não obtenção de consentimento por razóes imperativas impostas pelo direito interno em conformidade com o direito internacional relativo aos direitos humanos(15). Este é o caso implícito na Lei 12.654(16) quando torna obrigatória a identificação do perfil genético, mediante extração de DNA, por técnica adequada e indolor para os condenados por crime praticado, dolosamente, com violência de natureza grave contra pessoa, ou por qualquer dos crimes previstos no art. $1^{\circ}$ da Lei $n^{\circ}$ 8.072, de 25 de julho de 1990.

Do ponto de vista cultural, um dos maiores interferentes na expressão da autonomia durante o consentimento é o grau de instrução do sujeito. Para suplantar este entrave, tem-se buscado alternativas, como o uso da informação coletiva e alterações da linguagem utilizada no TCI sem, no entanto, esquecer-se das demandas normativas(7).

O trabalho buscou caracterizar a efetividade do processo de consentimento utilizado no Institu- 
to de Pesquisa e Perícias em Genética Forense do Departamento Geral de Polícia Técnico-Científica da Polícia Civil do Estado do Rio de Janeiro (IPPGF/DGPTC/PCERJ), isto é, da informação oral e do TCI oferecido aos doadores de material biológico para exames forenses. Todo material coletado pode ser utilizado também em pesquisas científicas, após a análise forense.

Ênfase foi dada à análise da legibilidade e adequação normativa do TCI. Tentou-se identificar o entendimento dos procedimentos de coleta e das fases de tratamento, utilização e conservação dos dados genéticos por parte dos doadores, a fim de verificar se realmente estavam consentindo de forma autônoma com os exames de DNA criminais.

\section{Material e métodos}

Foi alvo de análise o processo de consentimento, em especial o TCI utilizado entre 2005 e 2011 (anexo I) pelo IPPGF/DGPTC/PCERJ no ato da coleta de amostras biológicas para exames criminais de DNA.

A legibilidade foi avaliada a partir do índice de facilidade de leitura de Flesch (IFLF)(10) calculado com o uso do processador de texto Microsoft Office Word $2007^{\circ}$. Este índice baseia-se no comprimento de palavras e frases no texto, de acordo com a equação:

IFLF $=206,835-((1,015 \times$ comprimento médio da frase) $+0,846$ x (número de sílabas por 100 palavras))

A interpretação é feita variando de zero-difícil a cem-muito fácil(17). Os valores obtidos foram transformados em grau de instrução necessário para o entendimento de textos em português na forma proposta por Martins et al(18), como se segue:

$75<$ IFLS < 100, primeiro seguimento do Ensino Fundamental;

$50<$ IFLS $<74$, segundo seguimento do Ensino Fundamental;

$25<$ IFLS < 50, Ensino Médio;

$0<$ IFLS $<24$, Ensino Superior.
Para comparação do nível de instrução, foram obtidas informaçóes contidas em fichas cadastrais arquivadas no IPPGF de todos os 191 doadores de amostras que compareceram ao Instituto no ano de 2008.

Foi também verificado o enquadramento do TCI às recomendações da Resolução MS 196/96, bem como à Declaração Internacional sobre os Dados Genéticos Humanos que resumem bem as demandas legais atuais. Por fim, para a percepção direta do entendimento do processo pelo qual passariam após o consentindo e a condição sociocultural dos doadores. Foram entrevistados de forma aleatória com o uso de questionário estruturado com quatorze questôes fechadas, 67 doadores encaminhados a exames no IPPGF durante o ano 2011 que voluntariamente aceitavam responder após a doação do material biológico.

Durante a pesquisa foi mantido o mesmo procedimento de consentimento: após o cadastramento do doador, é feita uma explicação oral dos procedimentos de coleta e do processo de análise pelo qual passará o material genético, posteriormente, é passada uma via do TCI ao doador para leitura e decisão sobre o consentimento. Quando favorável ao procedimento, o TCI é assinado. No caso de recusa, termo próprio é oferecido. Também há termo próprio para menores e incapazes que é entregue ao responsável legal.

\section{Resultado e discussáo}

O TCI utilizado entre os anos de 2005 e 2011 pelo IPPGF apresentou índice de Flesch de 24. Isto significa uma legibilidade muito difícil, demandando para o seu entendimento, no mínimo, Ensino Superior do leitor. Importante constatação feita por Garrido e Garrido(19) foi que apesar da heterogeneidade, TCIs utilizados por um grande número de laboratórios de genética forense nacionais também apresentavam índice de legibilidade difícil ou muito difícil.

De forma geral, o grau de formação necessário para o entendimento do TCI mostra-se incompatível com o nível médio de formação dos doadores que foram encaminhados ao IPPGF durante o ano de 2008 (8,1 anos de estudo - Ensino Fundamental incompleto). Notadamente, o grau de ins- 
trução do sujeito é um dos maiores interferentes desta compreensão do TCI(10).

A tendência foi repetida quando analisados os resultados das entrevistas realizadas no ano de 2011. Em um grupo de 44 mulheres e 23 homens, com idade media $41 \pm 13,8$ anos, mais de $61 \%$ dos doadores apresentavam Ensino Fundamental ou menor escolaridade (tabela 1). Assumindo que a média de anos de estudo de pessoas com mais de 25 anos idade revela o nível de escolaridade do país e que em 2009 esse valor era de 7,1 anos (Ensino Fundamental incompleto)(20), a população encaminhada ao IPPGF apresentava nível de escolaridade bem próxima da média brasileira (7,2 anos).

Garantir a compreensão mais ampla possível do TCI seria a forma mais eficiente de promover a autonomia do doador $(5,7)$. Como exemplo, pode-se observar o trabalho de Falagas, Korbila, Giannopoulou et al (21), onde após avaliar o consentimento em 23 estudos de cirurgias e 30 ensaios clínicos, foram indicadas modificações importante no texto de consentimento informado a fim de garantir a eficácia das informaçôes. Para tanto, deve-se reconhecer que juntamente com o grau de instrução, prejudicam a compreensão do TCI o hábito da leitura e o aceso à internet(10). Entre os doadores entrevistados, a maior parte nunca acessa internet ou lê livros e jornais (Anexo tabela 1).

Além dos problemas de legibilidade, o TCI utilizado no IPPGF, assim como outros utilizados nesta atividade ao redor do país(19), não respondia às demandas normativas da Resolução 196/96 e da Declaração Internacional sobre os Dados Genéticos Humanos $(15,22)$. Entre os problemas mais importantes encontrados, estava a falta de informação quanto aos desconfortos e riscos; aos métodos alternativos para coleta da amostra; e à utilização e conservação dos dados genéticos.

Os métodos de coleta da amostra biológica utilizados no IPPGF, por exemplo, variaram nos últimos anos, partindo da punção venosa até o simples suabe de mucosa oral, em busca de oferecer maior conforto ao doador. Contudo, a não exposição da alternativa de métodos, permitindo a escolha do doador, provocou situaçôes bastante embaraçosas. Pois, vários doadores, praticamen- te recusavam-se a abrir a boca para a realização do procedimento. Tal constrangimento pode ser explicado pelo conceito de bucalidade descrito Botazzo(23) o qual, na busca de uma saúde oral completa, abarca questóes relacionadas à manducação e à linguagem, mas também às representaçóes subjetivas relacionadas ao erotismo do doador.

Nem mesmo a segunda via do TCI era entregue ao doador, como determinado por declaraçóes internacionais $(15,24)$ e por normas nacionais $(22,25,26)$ e código de ética profissional $(27)$. Este fato parece estar ligado à visão de que pesquisas e exames relacionados às investigaçóes criminais, como é o caso do fornecimento de amostras biológicas, impressóes digitais ou padrōes gráficos para exames de confronto, deve ser calcada na proteção da coletividade em detrimento das discussões sobre o consentimento e direitos individuais(13).

A tentativa de comprovar, a partir das entrevistas, o consentimento do doador sem o completo entendimento revelou uma realidade curiosa. A maioria dos doadores disse que leu o TCI, entretanto é assustador verificar que 45\% (tabela 1) dos doadores tomaram como base para suas decisóes exclusivamente a informação oral prestada por servidor que acompanharam a coleta, sequer lendo o TCI. A falta de leitura do termo certamente está relacionada ao não entendimento do mesmo.

A despeito de não lerem o TCI, a maioria achou o termo fácil e reconhecem que consentiram com o exame de DNA por comparação com outra amostra biológica, além de terem a correta percepção do sigilo de seus dados; de que nenhuma doença será diagnosticada a partir do material colhido; e que o dado anônimo poderá ser utilizado em pesquisas científicas (tabela 1).

A aparente contradição entre leitura do TCI realça a ideia de que o Consentimento informado é um processo que nas palavras de Goldim(28) deve envolver "respeito mútuo, diálogo, paciência e persistência na relação". Assim, a assinatura do TCI é apenas a última etapa de documentação do consentimento. Além disso, foi importante constar que a informação oral está chegando de forma 
correta e efetiva ao doados, pois esta apesar de seguir um script estabelecido, ainda era realizada de forma bastante empírica com forte expressão dos valores e conhecimentos do entrevistador.

Talvez a grande contradição encontrada nas respostas esteja no entendimento sobre o depósito dos dados genéticos em um banco informatizado. A maioria reconhece que não será utilizado qualquer banco de dados (tabela 1). Todavia, com o advento da Lei $\mathrm{n}^{\circ} 12.654$, que prevê a coleta de perfil genético como forma de identificação criminal, e que os dados genéticos deverão ser armazenados em banco de dados de perfis genéticos, faz-se necessário enfatizar este ponto durante todo o procedimento de consentimento. Pois, só serão isento do consentimento aqueles para os quais a referida lei torna obrigatória a coleta: condenados por crime praticado, dolosamente, com violência de natureza grave contra pessoa, ou por qualquer dos crimes previstos no art. 1ㅇa Lei no 8.072, de 25 de julho de 1990.

De forma geral, os resultados levam à percepção de aparente entendimento do processo. Contudo, não se pode negar que estes doadores são vulnerados culturalmente, pois o baixo grau de instrução e a carência de acesso às diferentes mídias escritas que corroboram os dados de Biondo-Simóes et al(10) são parâmetros que vulneram. Por outro lado, na situação policial, tentando localizar um ente desaparecido ou, ainda, de incriminar suspeitos, como nos crimes sexuais, ou livrar-se de acusaçóes, quando o próprio suspeito se propóe a oferecer material para exame, tornam-se suscetíveis a realizar qualquer procedimento que os acalente.

Nesse contexto, o papel do Estado na proteção e garantia da integridade dos doadores não pode ser negligenciado(29). Especialmente em pesquisas que envolvam questôes sobre uso de drogas, violência doméstica, crime organizado, abuso se$\operatorname{xual}(30)$.

\section{Conclusão}

O TCI utilizado entre 2005 e 2011 pelo IPPGF apresenta legibilidade inadequada ao grau de instrução da média da população que utiliza os serviços de Genética Forense no Estado do Rio de Janeiro, o que não difere da realidade brasileira. Além disso, o TCI apresentava várias deficiências no que diz respeito às demandas da Resolução 196/96 e à Declaração Internacional sobre os Dados Genéticos Humanos.

Apesar desta constatação, em um grupo de entrevistados que passaram durante o ano de 2010, foi possível constatar a eficiência do processo a partir da percepçáo do entendimento do processo por qual o doador e, posteriormente, seus dados genéticos passariam. Contudo, ficou claro também que muitas vezes o TCI não é lido, talvez pela baixa legibilidade ou pelo contato restrito com a leitura apresentada pelos doares. Dessa forma, consentem baseados na informaçáo oral que lhes é passada, a qual é entrevistador.

Os problemas do processo de obtenção do consentimento somado à vulnerabilidade cultural e social dos doadores e à suscetibilidade provocada pela situação policial resultam em um consentimento que não representa a expressão autônoma do doador.

Os resultados da análise levaram a profundas mudanças no procedimento de obtenção de consentimento para exames de DNA criminais no IPPGF. Especialmente o TCI (Anexo II) teve sua legibilidade facilitada e enquadrou-se melhor às demandas normativas em vigor.

\section{Agradecimentos}

À FAPERJ pelo fomento; à Maria de Fátima César de Oliveira, David Prata Borges de Medeiros, Kátia Araújo e Ana Lúcia Cardoso Alves pelo apoio na obtenção dos dados, tabulação dos resultados e discussões. 


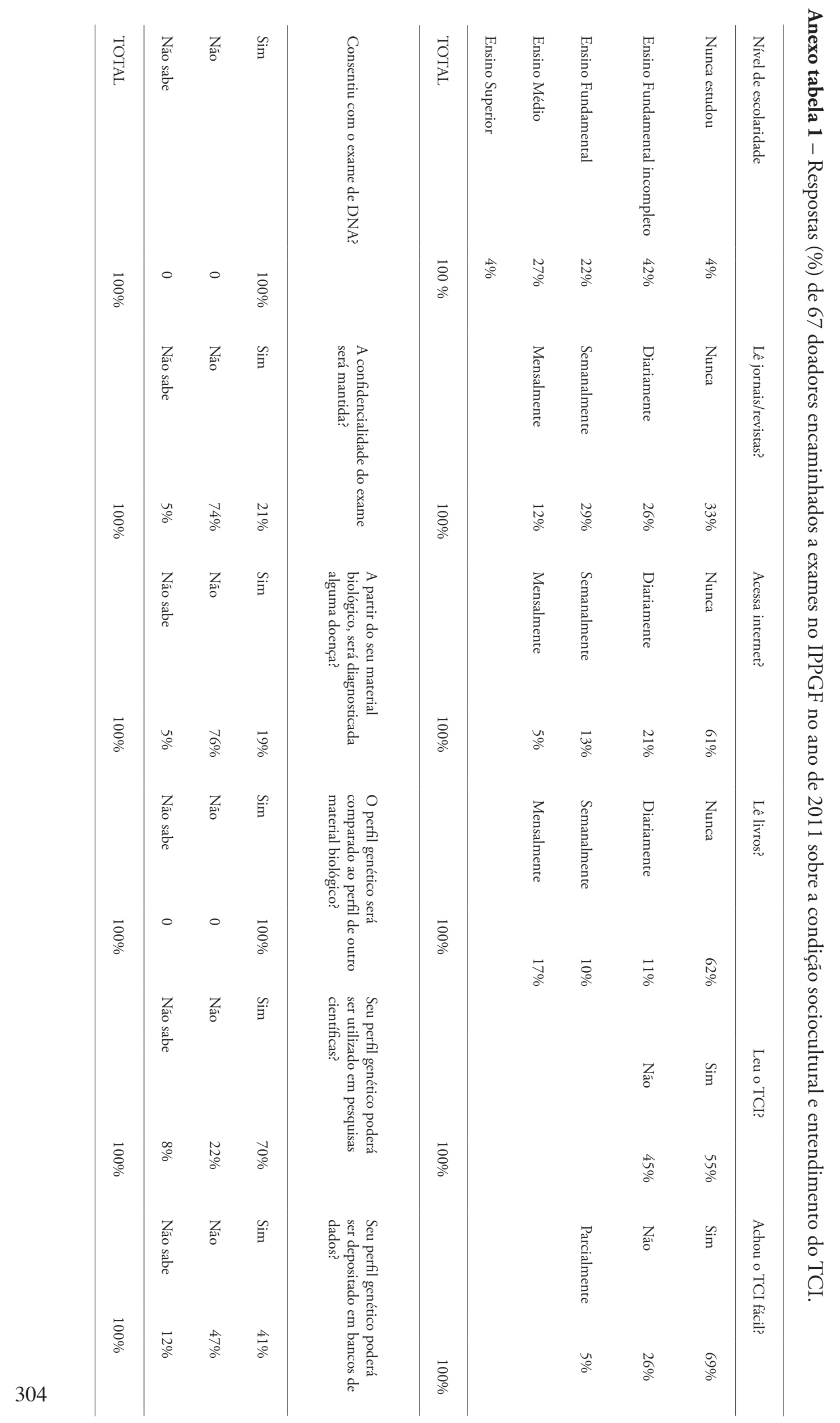




\section{Anexo I- Termo de Consentimento Informado utilizado entre 2005 e 2011 pelo IPPGF}

Considerando os princípios elencados na Constituição da República Federativa do Brasil, promulgada em 05 de outubro de 1988 e atendendo ao que refere o artigo $5^{\circ}$ e seus incisos, eu

RG emi-

tido pelo , $\mathrm{CPF}$

concordo de livre e espontânea vontade a submeter-me a coleta de material biológico, com a finalidade de realizar exame de Investigação de Vínculo Genético junto ao IPPGF / DGPTC da PCERJ, assumindo a responsabilidade por qualquer consequência advinda desta prática. Declaro, ainda, que concordo que uma amostra de meu material genético seja objeto de pesquisa científica, como alíquota anônima. As informaçóes contidas neste documento são verdadeiras.

\section{Anexo II -Termo de Consentimento Informado utilizado a partir de 2012 pelo IPPGF}

$\mathrm{Eu}$,

_, autorizo, de livre e espontânea vontade, a coleta de material biológico, células da mucosa oral ou sangue, para servir como padrão de confronto em identificação humana pelo DNA no evento em questão.
Reconheço que, se coletadas células da mucosa oral, os desconfortos e riscos serão bastante restritos, pois será apenas passada uma haste com algodão na minha gengiva. No caso de coleta de sangue, será feita uma pequena perfuração na extremidade de um dedo com uso de agulha ou lanceta estéril e descartável, o que provocará pequeno desconforto.

Tenho ciência de que não haverá qualquer custo ou compensação financeira.

Concordo que a informação genética seja depositada em banco de dados com fins criminais e utilizada de forma anônima em pesquisas científicas para caracterizaçáo da população brasileira. No entanto, poderei retirar o consentimento a qualquer momento.

Declaro não possuir irmão gêmeo idêntico e não ter sido submetido à transfusão de sangue ou transplante de medula óssea nos últimos 120 dias.

Estando ciente e, de acordo, assino o presente termo na presença daqueles que acompanharam o procedimento.

\section{Referências}

1. Gomes EdeC. Perícias Genéticas, Paternidade e Responsabilidade pela Procriação. In: Martins-Costa J, Möller Ll. (Org) Bioética e Responsabilidade 2009; 361-390.

2. Medeiros RJ. A Genética na Prova Penal. Ed. Pilares; 2009.

3. Avena NCP. Processo Penal Esquematizado. Forense; 2009.

4. Cho MK, Sankar P. Forensic genetics and ethical, legal and social implications beyond the clinic. Nature Genetics 2004; 36: S8-S12.

5. Menegon VM. Consentindo ambigüidades: uma análise documental dos termos de consentimento informado, utilizado em clínicas de reprodução humana assistida. Cad. Saúde Pública 2004; 20(3): 845-854.

6. Almeida LD. Suscetibilidade: novo sentido para a vulnerabilidade. Revista Bioética 2010; 18(3): 537-548.

7. Goldim JR. O Processo de Consentimento Livre e Esclarecido em Pesquisa: uma nova abordagem. Rev Assoc Med Bas 2003; 49(4): 372-374.

8. EUA contra Karl Brandt et al. The Medical Case, Trials of War Criminals before the Nuremberg Military Tribunal under Control. Council Law 1946; 2(10): 83.

9. Annas GJ. Globalized Clinical Trials and Informed Consent. N Engl J Med 2009; 360(20): 2050-2053.

10. Biondo-Simóes MdeLP, Martynetz J, Ueda FMK, Olandoski M. Compreensão do Termo de Consentimento Informado. Rev Col Bras Cir 2007; 34(3): 183-188.

11. Boy R, Schramm FR. Bioética da proteçáo e tratamento de doenças genéticas raras no Brasil: o caso das doenças de depósito lisossomal. Cad Saúde Pública 2009; 25(6): 1276-1284.

12. Kottow MH. The vulnerable and the susceptible. Bioethics 2003; 17(5-6): 460-471.

13. Garrido RG. Consentimento Livre e Esclarecido em Genética Forense: intervençóes necessárias. In: I Congresso Nacional Diversidade, Ética e Direitos Humanos, 2010, Itapetinga, v. Único: 01-08.

14. Garrido RG. Evolução dos Processos de Identificação Humana: das características antropométricas ao DNA. Genética na Escola 2009; 5: 38-40. 
15. UNESCO. International Declaration on Human Genetic Data; 2003.

16. Brasil. Lei $n^{\circ} 12.654$, de 28 de maio de 2012. Altera as Leis nos 12.037 , de $1^{\text {o }}$ de outubro de 2009, e 7.210, de 11 de julho de 1984 - Lei de Execução Penal, para prever a coleta de perfil genético como forma de identificação criminal, e dá outras providências.

17. Goldim JR. Índices de legibilidade de Flesch-Kincard e de facilidade de leitura de Flesch. Disponível em URL: http:// www.bioetica.ufrgs.br Acesso em 02 jan 2012.

18. Martins TBF, Ghiraldelo CM, Nunes MGV, Oliveira JON. Readability Formulas Applied to Textbooks in Brazilian Portuguese. Notas do ICMSC-USP, Série Computação 1996; 28.

19. Garrido RG, Garrido FSRG. Free and Informed Consent (FIC) in Forensic Genetics: Consent without Understanding? In: III Congresso Brasileiro de Genética Forense. Porto Alegre-RS; 2011.

20. IBGE. Síntese de indicadores sociais: uma análise das condiçóes de vida da população brasileira 2010. Estudos e Pesquisas Informação Demográfica e Socioeconômica 2010; 27.

21. Falagas ME, Korbila IP, Giannopoulou KP, et al. Informed consent: how much and what do patients understand? $A m$ J Surg 2009; 198: 420-435.

22. Brasil. Ministério da Saúde. Resolução 196/96 do Conselho Nacional de Saúde/MS Sobre Diretrizes e Normas Regulamentadoras de Pesquisa envolvendo seres humanos. Diário Oficial da União, Brasília, 10 de outubro de 1996.

23. Botazzo C. Sobre a bucalidade: notas para a pesquisa e contribuição ao debate. Ciência \& Saúde Coletiva 2006; 11(1): 7-17

24. WHO. International ethical guidelines for biomedical research involving human subjects. Genebra: CIOMS, OMS; 1993.

25. Brasil. Lei 8.078 de 11 de setembro 1990. Dispóe sobre a proteção do consumidor e dá outras providências. Brasília; 1990.

26. Brasil. Lei 10.406 de 10 de janeiro de 2002. Institui o Código Civil. Brasília; 2002.

27. Brasil. Resolução 1.246 de 08 de janeiro de 1988. Dispóe sobre o Código de ética Médica. Diário Oficial da União, Brasília. 26 de janeiro de 1988, seção 1: 1574-1577.

28. Goldim JR. O Consentimento Informado numa perspectiva além da autonomia. In: Alho C, Feijó A, Gauer G, et al. (orgs.) Ciência e Ética. Os Grandes Desafios. EDPUCRS; 2005: 45-64.

29. Schramm FR, Kottow M. Principios bioéticos en salud pública: limitaciones y propuestas. Cad Saúde Pública 2001; 17: 949-956.

30. Concone MHVB, Cerveny CMdeO. Research and the (free and) informed consent. Ciência \& Saúde Coletiva 2008; 13(2): 341-349.

Recebido: 12 de junho de 2012

Aceito: 14 de agosto de 2012 